\title{
DEVELOPMENT OF LIFE EXPECTANCY IN THE CZECH REPUBLIC IN YEARS 1920-2010 WITH AN OUTLOOK TO 2050
}

\author{
Markéta Arltová, Jitka Langhamrová, Jana Langhamrová*
}

\begin{abstract}
:
At present the majority of advanced countries are dealing with the problem of the ageing of the population. The Czech Republic is no exception. Demographic ageing is caused by the fact that mortality is dropping, especially infant mortality, and this expectation of life at birth. At the same time the birth rate is declining and subsequently total fertility rate drops below the preservation level of simple reproduction, which means that there are less children and more persons in particular in the older and oldest age-groups. It is very important to realise that the changes in the level of mortality bring with them positive impacts in lengthening of life expectancy on the one hand, but on the other hand, there is significant demographic ageing of the population. In this contribution we would like to show how the life expectancy has developed in the Czech Republic in a historical context and how it might develop in the coming years. For professionals the application of the Lee-Carter method will certainly be interesting - this is a method commonly used in the world by demographers and actuaries for modelling the future development of mortality and it is also the basic method used for stochastic demographic projections.
\end{abstract}

Keywords: ageing of population, life expectancy, Lee-Carter method, co-integration

JEL Classification: C18, C53, J11

\section{Introduction}

Currently most developed countries are facing the problem of a population ageing. The Czech Republic is no exception. Demographic ageing is due to a reduction in mortality, above all mortality in older age. However, in the past falling infant mortality at birth significantly contributed to prolonging life expectancy. Today this is at a very low level and therefore currently virtually does not contribute too much to prolonging life expectancy at birth. The birth rate is falling concurrently with mortality. There are fewer children and the number of people of an older or oldest age group is increasing. It is very important to be aware of the fact that changes in the level of mortality also bring a positive impact in the form of the prolongation of life expectancy on the one hand, whereas there is significant demographic ageing of the population on the other hand. This has and will have an impact on the pension and health insurance sector and the insurance sector as a whole. Some pension funds worry whether they will be

* Markéta Arltová, Jitka Langhamrová, Jana Langhamrová, University of Economics, Prague (arltova@vse.cz; langhamj@vse.cz, xlanj18@vse.cz). This paper was written with the support of the Grant Agency of the Czech Republic under No. 402/09/0369 "Modelling of Demographic Time Series in the Czech Republic“. 
able to meet their obligations in future because in view of the longer life expectancy in retirement age they will have to pay out pension for a longer period than they had originally expected.

In this article we would like to show how life expectancy developed in the Czech Republic through the historical context and how it could develop in the years to come. The application of the Lee-Carter method will certainly interest experts as it is regularly applied by demographers and actuaries worldwide for modelling the future trend of mortality and it is the basic method for stochastic demographic projections.

\section{Why Is Life Expectancy Longer and What Are Its Consequences?}

Throughout the existence of humanity there has never been such a rapid increase in population numbers in the world as has occurred in about the last two hundred years. In the past the population grew slowly above all because the numbers of children born alive slightly exceeded the numbers of those born dead. The birth rate of the population served as the main way to regulate the number of people in society. As soon as the process of modernisation began major changes appeared in the level of crude death rate and crude birth rate. The population moved from the traditional regime of reproduction (where there was a high crude death rate and a crude birth rate) to a modern regime (where there was a low crude death rate and a crude birth rate). The population firstly gets younger and then there is demographic ageing. In terms of demographic behaviour there are changes which are called the "demographic revolution" or "demographic transition" in literature. These changes came about above all due to advances made in medicine, improvements in the level of the population's hygiene and rise in the standard of living. The rise of industrialisation and urbanisation increased the number of people living in cities. The fall in the crude death rate during the demographic revolution was caused above all by a fall in the mortality of newlyborns, infants, children and mothers. Just as more young people survive so the number of young people in the population increases. More young people live to parental age and therefore the number of births increases.

The population may age in two ways. The first of these is the relative ageing of the population caused by a fall in the birth rate and thereby there is a fall in the number of children in the population. The second type of ageing is absolute ageing caused by a fall in mortality and rise in life expectancy resulting in an increase in older people in the population. Whether the population gets younger or older depends on the nature of the age structure in the past and on the current situating concerning the birth rate and mortality. In the past the high mortality rate resulted in shorter expectation of life at birth.

Expectation of life at birth in the long-term was hugely affected by the level of infant and child mortality as high maternal mortality also had an effect in the past. However, low expectation of life at birth does not mean that people cannot live to a greater age if they survive the period of high mortality in early life. Just as the living and economic 
conditions of the population improved so life expectancy rose continuously and more people survived to a higher age. The most significant changes were recorded in modern societies in the second half of the $19^{\text {th }}$ century. At this time expectation of life at birth in the world disregarding the sex equally ranged on average at about 41 years of age and by 1900 it increased to 50 years of age (Rabušic, 1993). In 1930 the highest value of this indicator was 62 years and by 1965 it was almost 72 years disregarding the sex equally. In the Czech lands the value of expectation of life at birth ranged in years 1899-1902 for men at about 38.9 years and for women at about 41.7 years (Kučera, 1990). In 1930 it was about 54 years for men and 58 years for women, and in 1965 the value of expectation of life at birth was already at about 67 years for men and more than 73 years for women. Today expectation of life at birth disregarding the sex in the most developed countries is about 80 years (Figures 1 and 2).

Several factors have contributed to the growth of expectation of life at birth. What first applied was that a higher level of mortality was recorded in higher income areas. We can also ask ourselves the question how this could be possible for people with higher incomes and better housing, food, healthcare, etc. In the pre-industrial period in Europe these people lived in cities and their outskirts. What applied in this period was that in areas with a higher concentration of people the common cause of death was an infectious or parasitic disease. There were great epidemics at a time when hygiene measures in the cities were still inadequate to prevent the rapid spread of these diseases. Likewise immigrants did not have sufficient immunity against diseases and often succumbed to them. According to historical demographers what applied at the time was that in the agricultural regions of Europe where there was no high concentration of population there was hope for greater life expectancy (45-50 years) than in the cities (30-33 years). As society gradually developed it was possible to make greater investments into healthcare. In the $19^{\text {th }}$ century hospitals began to be built in Europe and this is the time of the discoveries made by Koch and Pasteur. People began to realise the importance of the principles of hygiene in the fight against infectious diseases, built water mains as a source of safe drinking water, began building sewer systems and as a consequence the occurrence of greater epidemics decreased significantly. People became urbanised and what came to apply was that there was longer life expectancy in the higher income areas.

In the 1960s there were significant advances in medicine. The length of life expectancy significantly increased as did the number of people of older age groups. There was a significant ageing of the population in developed countries due to very low mortality. A large part of the population of these countries began to live until the age of 65 , and an ever greater number lived until the age of 85 . The fall in mortality was marked above all in older age groups and just as specific mortality of old people fell so life expectancy rose. 


\section{Figure 1}

Expectation of Life at Birth for Men for Selected European Countries in 1850-2010

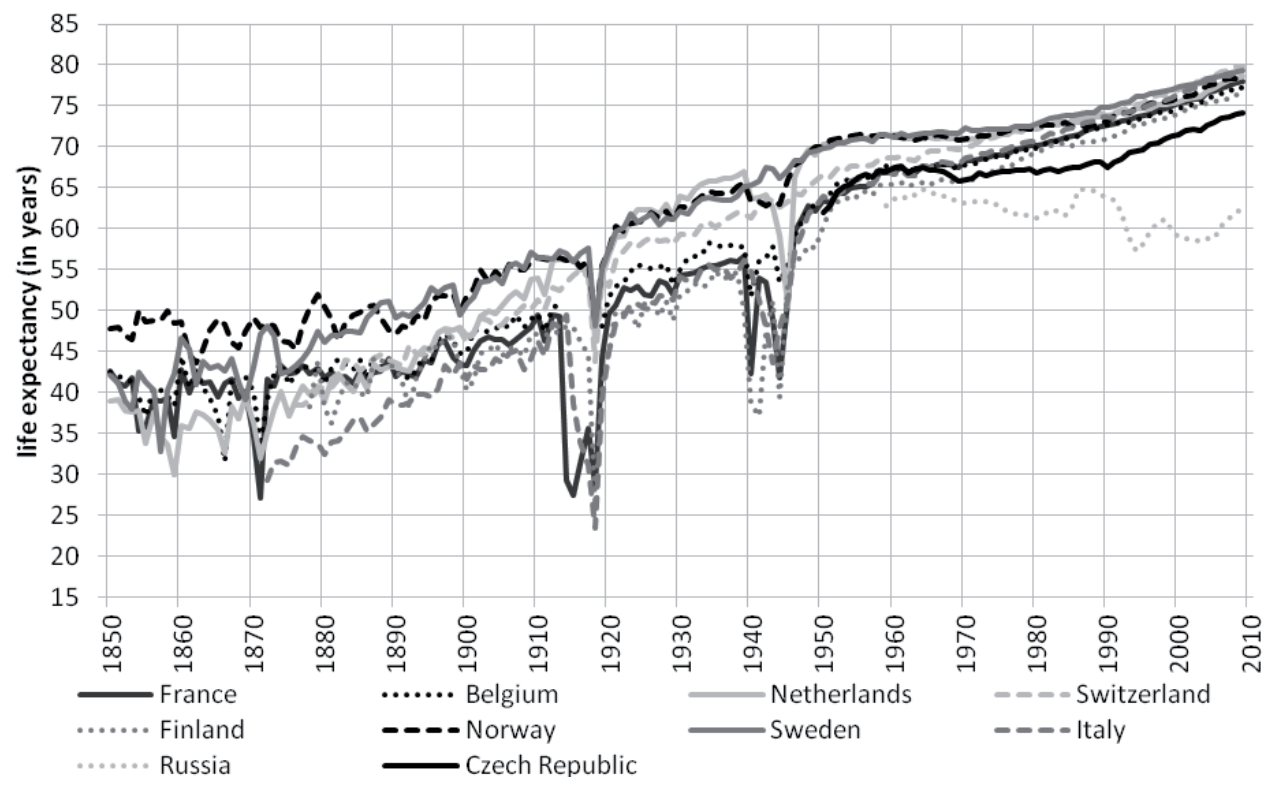

Source: data CZSO, data HMD, own calculations

Figure 2

Expectation of Life at Birth for Women for Selected European Countries in 1850-2010

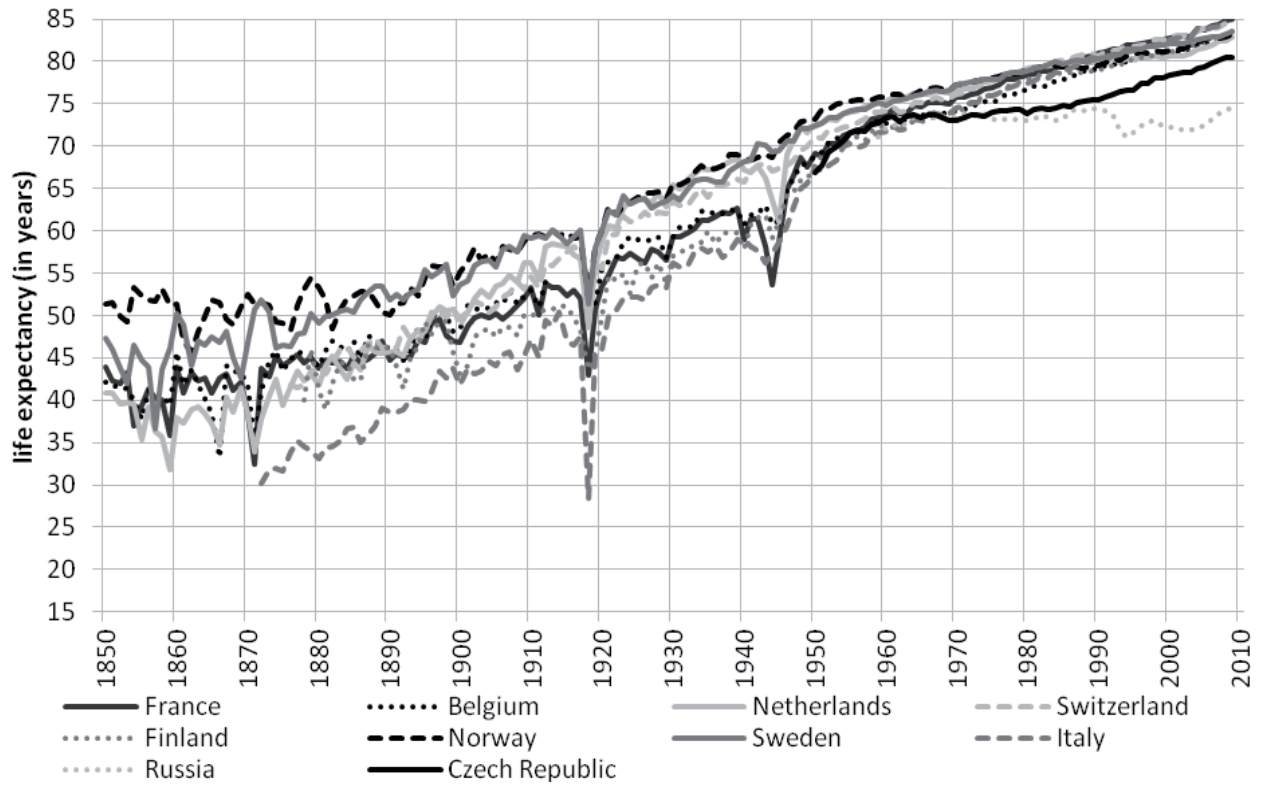

Source: data CZSO, data HMD, own calculations 
Many experts are asking the questions such as where the limit of human age is, how long we will live, whether people will live to a greater age in good health, whether the years of added active life will be without sickness or whether people will be sick and self-reliant. Will it be possible to slow down or delay ageing in some way? Longevity is inherited, it relies on lifestyle, diseases and so on. According to Wolf (1982) potential life expectancy is 90-100 years, some demographers even speak of death before the age of 90 as being premature (Kučera, 1990), while, on the other hand, they are becoming more aware of what significant growth in the number of older people in the population means. There is the question of essential health and social care costs with all the economic, social and political repercussions.

\section{Life Expectancy in the Czech Republic in Years 1920-2010}

Life expectancy is one of the most important demographic indicators as in one figure it provides aggregate information about specific mortalities according to age and sex. The most common information presented is the expectation of life at birth $e_{0}^{0}$, which is the average number of years, which can live a newly born under the current mortality. Data for the calculation of life expectancy in the Czech Republic since 1920 can be found on the website of the Czech Statistical Office. Separate mortality tables for men and women are taken into account. Figure 3 shows a comparison of expectation of life at birth and the precise age of 1 for men and women and the infant mortality quotient in years 1920-2010.

Figure 3

Expectation of Life at Birth and Life Expectancy for One Year Old Men and Women and Quotient of Infant Mortality in 1920-2010

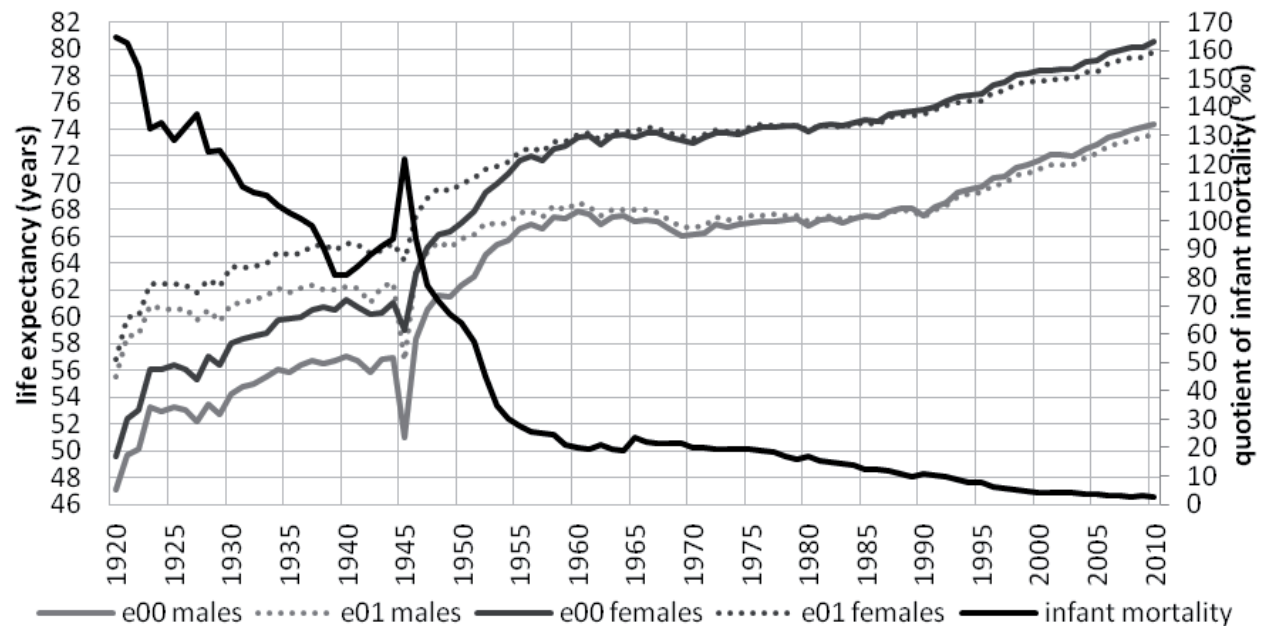


It is generally known that the values of life expectancy are affected by the development of mortality in relevant years. This effect is reflected in the form of noticeable fluctuations and changes in the trend of monitored indicators and it is therefore appropriate to briefly mention the development of mortality in the territory of today's Czech Republic.

In the early $20^{\text {th }}$ century the population living in our territory had a high level of the crude death rate. The highest value was recorded in 1918 as a result of the Spanish flu pandemic, this was followed in years 1923-1925 by its decline and further short-term increases were caused by the flu epidemics in years 1927 and 1929. A noticeable decline in the crude death rate continued, with the exception of the period of the Second World War, until the early 1950s. It was assumed that due to the new medical discoveries, vaccination and prevention epidemics would disappear that to a great extent had contributed to high mortality and that mortality would fall even more. Epidemics really did disappear while pneumonia and flu were no longer a direct cause of death, but mortality did not fall because diseases of the circulatory system and cancer causing death came to the fore. The time when mortality caused by these diseases grew and compensated the smaller number of deaths to infectious diseases lasted about 20 years. After this intermediate period, above all due to the improving living conditions and new medical methods of treatment, mortality in the Czech Republic began to fall from the mid-1980s.

Figure 3 clearly shows that at the start of the monitored period the level of infant mortality was greatly unfavourable reaching almost 165 per mille. During the next few years infant mortality gradually fell sharply with some minor fluctuations until the 1960s (with the exception of 1945, when a significant fluctuation was recorded caused by worse hygiene conditions at the end of the Second World War) to the value of about 20 per mille. In the 1970s the value of infant mortality was still about 22-24 dead children within one year per thousand children born alive. In view of improved hygiene conditions and the very good standard of paediatric care it fell from these values right down to 3-4 per mille, therefore almost seven times compared with 1960, and in 2010 it even fell down to the value of 2.7 per mille which is one of the lowest values throughout Europe and the lowest level in the history of the Czech Republic.

Life expectancy is presented separately for each sex due to the different level of mortality in men and women. Figure 3 shows the clear difference between expectation of life at birth of men and women and also the difference between expectation of life at birth and life expectancy of a person at the precise age of 1. It may seem illogical that expectation of life at birth is shorter than life expectancy of a person at the age of 1 . This is caused by expectation of life at birth being the average age of the deceased in a model population (in the so-called stationary population) and is therefore affected by infant mortality. A greater difference between expectation of life at birth and life expectancy of a precisely 1 year-old person could be recorded for girls only from 1981 and not until from 1985 for boys. The reason is the above described fall in infant mortality. This clearly shows that infant mortality and its very low level no longer provides much space for the future increase of expectation of life at birth.

Data about the development of expectation of life at birth shows that since 2010 there has been a $58 \%$ increase compared with 1920 . The increase in life expectancy at birth of 
women is $62 \%$ compared with 1920, of course since 2004 there has been a more rapid increase of life expectancy of women in the 68-75 age groups. This increase is evidently caused by better mortality ratios in women of higher age groups. Generally speaking life expectancy was prolonged in time above all with the fall in infant mortality. Currently its prolongation is affected above all by the fall in mortality in middle and higher age groups due to a fall in deaths from diseases of the circulatory system in men and women.

Table 1

Life Expectancy for Certain Ages in Selected Years in the Czech Republic

\begin{tabular}{|l|c|c|c|c|c|c|c|c|c|c|}
\hline & \multicolumn{4}{|c|}{ Men } & \multicolumn{5}{c|}{ Women } \\
\cline { 2 - 12 } & $\begin{array}{c}\mathbf{0} \text { year } \\
\text { old }\end{array}$ & $\begin{array}{c}\mathbf{2 0} \text { year } \\
\text { old }\end{array}$ & $\begin{array}{c}\mathbf{4 0} \text { year } \\
\text { old }\end{array}$ & $\begin{array}{c}\mathbf{6 0} \text { year } \\
\text { old }\end{array}$ & $\begin{array}{c}\mathbf{8 0} \text { year } \\
\text { old }\end{array}$ & $\begin{array}{c}\text { 0 year } \\
\text { old }\end{array}$ & $\begin{array}{c}\mathbf{2 0} \text { year } \\
\text { old }\end{array}$ & $\begin{array}{c}\mathbf{4 0} \text { year } \\
\text { old }\end{array}$ & $\begin{array}{c}\mathbf{6 0} \text { year } \\
\text { old }\end{array}$ & $\begin{array}{c}\mathbf{8 0} \text { year } \\
\text { old }\end{array}$ \\
\hline $\mathbf{1 9 2 0}$ & 47.05 & 42.47 & 27.79 & 13.81 & 4.72 & 49.60 & 43.32 & 28.72 & 14.14 & 4.73 \\
\hline $\mathbf{1 9 3 0}$ & 54.22 & 45.73 & 29.34 & 14.78 & 4.90 & 58.04 & 48.49 & 31.83 & 15.97 & 5.34 \\
\hline $\mathbf{1 9 4 0}$ & 57.10 & 46.19 & 28.86 & 14.11 & 4.33 & 61.29 & 49.31 & 31.89 & 15.69 & 4.78 \\
\hline $\mathbf{1 9 5 0}$ & 62.31 & 48.51 & 30.64 & 14.96 & 5.29 & 67.00 & 52.26 & 33.88 & 16.88 & 5.31 \\
\hline $\mathbf{1 9 6 0}$ & 67.92 & 50.39 & 31.95 & 15.56 & 5.56 & 73.40 & 55.22 & 36.02 & 18.39 & 5.74 \\
\hline $\mathbf{1 9 7 0}$ & 66.13 & 48.49 & 30.11 & 14.11 & 5.05 & 73.02 & 54.85 & 35.59 & 17.96 & 5.67 \\
\hline $\mathbf{1 9 8 0}$ & 66.81 & 48.75 & 30.06 & 14.31 & 4.64 & 73.86 & 55.34 & 35.91 & 18.17 & 5.57 \\
\hline $\mathbf{1 9 9 0}$ & 67.58 & 48.90 & 30.19 & 14.58 & 5.05 & 75.42 & 56.45 & 37.00 & 19.14 & 6.25 \\
\hline $\mathbf{2 0 0 0}$ & 71.65 & 52.37 & 33.43 & 17.02 & 6.11 & 78.35 & 58.91 & 39.34 & 21.21 & 7.09 \\
\hline $\mathbf{2 0 1 0}$ & 74.37 & 54.86 & 35.73 & 18.69 & 6.62 & 80.60 & 60.99 & 41.35 & 22.91 & 7.91 \\
\hline
\end{tabular}

Source: data CZSO, own calculations

Figure 4

Difference in Life Expectancy of Women and Men in Certain Ages and Selected Years in the Czech Republic

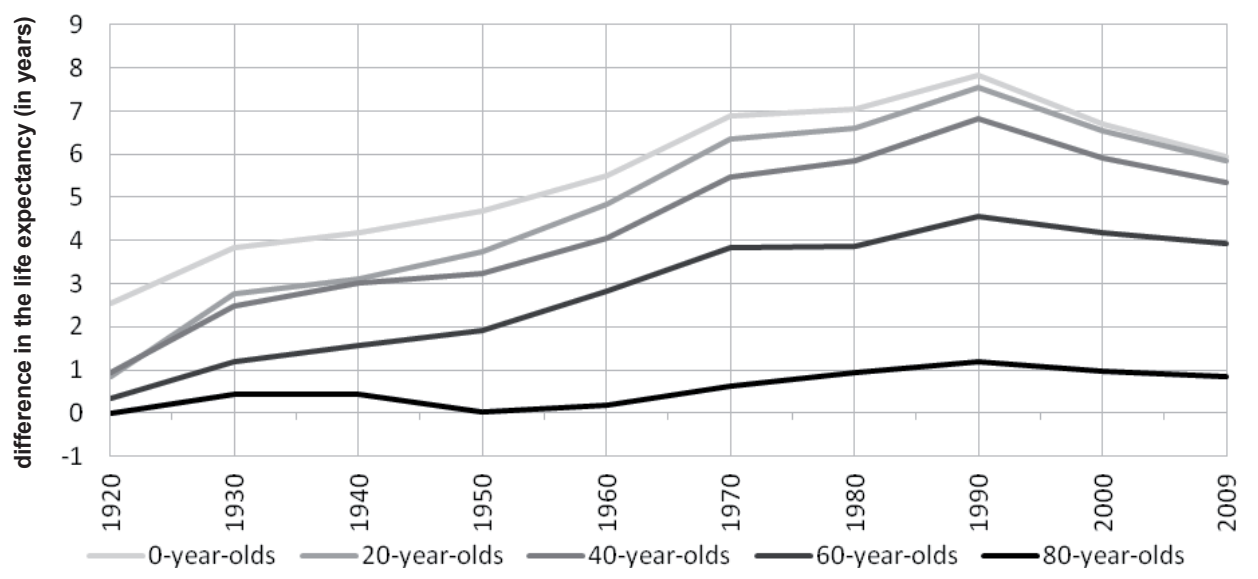

Source: data CZSO, own calculations 
Therefore as life expectancy of men and women is being prolonged, it is interesting to monitor the trend of life expectancy in selected ages. Figure 4 clearly shows male excess mortality, which means that in all age groups women have longer life expectancy than men. The lower the age the higher the difference is in time. Why men have an almost 7 -year lower life expectancy than women at the start of life is a frequent question. This phenomenon is caused by a generally higher intensity of male mortality rates in all age groups. However, if men live to a greater age they have about the same life expectancy as women.

Figure 5

Development of Life Expectancy in Selected Ages in 1920-2010

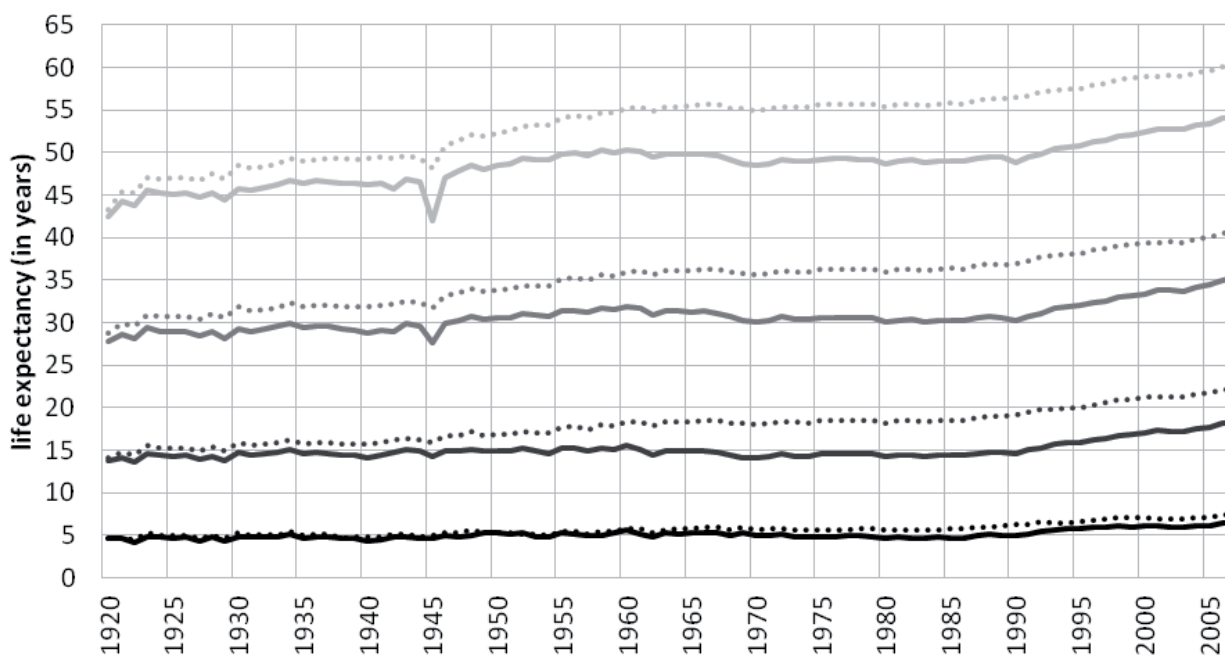

Source: data CZSO, own calculations

An interesting outlook on the trend of life expectancy is from the outlook of the so-called paradox of life expectancy which is usually used only for comparing the life expectancy of a newly born person and a precisely one-year-old person. Looking in more detail at the life expectancy of person in childhood it can be seen that in the past even the life expectancy of a precisely 13-year-old person was longer than the life expectancy of a person at birth. For example, in 1920 life expectancy for a precisely 13-year-oldboy was higher than in a child born in the same year, and the same applied in 1920 for a precisely 12 -year-old girl. It was caused by high infant and child mortality.

Table 2 contains differences between life expectancies of a newly born and a precisely one-year-old child for selected years in the period of 1920-2010. It is apparent that due to the improved level of infant mortality there is a gradual increase in the value of expectation of life at birth due to this until the complete disappearance of the life expectancy paradox for both sexes. 
Table 2

Difference in the Expectation of Life at Birth and Life Expectancy of One Year Old Person in Selected Years in the Czech Republic

\begin{tabular}{|l|c|c|c|c|c|c|c|c|c|c|}
\hline & 1920 & 1930 & 1940 & 1950 & 1960 & 1970 & 1980 & 1990 & 2000 & 2010 \\
\hline Males & -8.48 & -6.75 & -5.15 & -3.56 & -0.57 & -0.53 & -0.31 & 0.16 & 0.67 & 0.79 \\
\hline Females & -7.24 & -5.70 & -4.25 & -2.94 & -0.25 & -0.28 & -0.05 & 0.31 & 0.72 & 0.80 \\
\hline
\end{tabular}

Source: data CZSO, own calculations

\section{Estimated Life Expectancy in the Czech to 2050}

Modelling and forecasting of life expectancy is part of the so-called population forecasts. These forecasts are prospective estimates of the future trend in the number, age and sexual structure of the population and is part of social and political forecasts because they play a crucial role in many social, political and economic decisions, such as in financing the pension and healthcare systems, in the trend of the labour market or in education. Unlike standard economic forecasts they are to build a specific methodological mechanism due to which, in comparison with traditional forecasting methods, they can work in unusually long time horizons of 50 and more years.

Population forecasts are most frequently based on deterministic models and are usually calculated in three different variants of future development - low, medium and high. In each variant the demographic factors are estimated on the basis of the extrapolation of actual values and include various preconditions for the development of individual components of population development. The application of deterministic models for forecasting is very popular because these models are very simple. However, the simplicity is balanced out by considerable disadvantages - for example the probability aspect is not considered here, the resulting size of the population occurs with the same probability in the entire time interval and perfect, but unrealistic relations are assumed between the demographic components (Härdle and Myšičková, 2009).

Forecasts based on stochastic models of time series began to appear during the 1990s. The impulse was the development of the Lee-Carter method (Lee, Carter, 1992) for forecasting mortality. This method is based on the forecasting of historical time series of age specific mortality rates using standard procedures of time series analysis. After various modifications, such as Lee, Miller (2001), Brouhns, Denuit, Vermunt (2002), Renshaw, Haberman (2006), this method became the most commonly applied and today it is difficult to imagine any population forecast without its application (it is also used by the U.S. Census Bureau in its estimates of world population).

\section{Lee-Carter Method}

The Lee-Carter method is used for forecasting life expectancy. Its principle is relatively simple and involves the modelling of age specific mortality in time based on the following model 


$$
\ln \left(m_{x, t}\right)=\alpha_{x}+\beta_{x} \gamma_{t}+\varepsilon_{x, t}, \quad x=0,1, \ldots, \omega-1, t=1,2, \ldots, T,
$$

where $m_{x, t}$ are specific mortality rates at age $x$ and in time $t$, constituting $\omega-1 \mathrm{x} T$ by dimensional matrix $\boldsymbol{M}$ of specific mortality rates at age $x$ and in time $t, e^{\alpha_{x}}$ is the average profile of mortality at age $x$ (irrespective of time $t$ ), $\beta_{x}$ is the age specific constant which represents the speed of fluctuation of mortality at a given age, as opposed to the total level of mortality $\gamma_{t}$ in time $t\left(\gamma_{t}\right.$ can also be described as the total mortality index) and $\varepsilon_{x, t}$ is white noise. The identification model is ensured by conditions $\sum_{t=1}^{T} \gamma_{t}=0$ a $\sum_{x}^{\omega-1} \beta_{x}=1$. The LC method is a special case of the method of main components in which the data on the logarithms of age specific mortality rates is summed up only into one component $\gamma_{t}$, which explains the biggest share of data variability resulting in the reduction of the dimensionality of matrix $\boldsymbol{M}$.

Lee and Carter (1992) also proposed a second estimate stage, i.e. adjustment $\hat{\gamma}_{t}$ so that it would be guaranteed that the total number of deceased $M_{t}=\sum_{x=1}^{\omega-1} M_{x, t}$ will be equal to
the total number of deceased estimated by the model, i.e.

$$
M_{t}=\hat{M}_{t}=\sum_{x=0}^{\omega-1} \bar{S}_{x, t} e^{\left(\hat{\alpha}_{x}+\hat{\beta}_{x} \hat{\gamma}_{t}\right)}
$$

where $\bar{S}_{x, t}$ is the medium state of the population at $x$ and in time $t$. This adjustment was modified in various ways such as by Wilmoth (1993) or Lee and Miller (2001).

The construction of the forecast is based on the fact that parameters $\hat{\alpha}_{x}$ and $\hat{\beta}_{x}$ are constant in time and the total mortality index $\hat{\gamma}_{t}$, which is a one-dimensional time series, is modelled and forecast on the basis of the Box-Jenkins methodology (Box, Jenkins, 1970). ARIMA models are used to calculate forecast and subsequently using estimates of parameters $\hat{\alpha}_{x}$ and $\hat{\beta}_{x}$ the forecast is obtained of age specific mortality rates from the relationship of

$$
\hat{m}_{x, t}=e^{\hat{\alpha}_{x}+\hat{\beta}_{x} \hat{\gamma}_{t}}, \quad x=0, \ldots, 100+, t=2009, \ldots, 2050
$$

However, if the Lee-Carter method is applied for estimating the life expectancy forecast a problem arises which involves gaining estimates of life expectancy separately for men and women. For this reason the LC method is applied separately to age specific mortality rates of men and women, and thereby estimates of mortality indexes are obtained also for each sex separately $\left(\hat{\gamma}_{t}^{W}, \hat{\gamma}_{t}^{M}\right)$. However if both indexes of the ARIMA models are used to obtain a forecast, their forecasts in time diverge unrealistically.

This problem may be resolved with the help of the application of multidimensional time series methods to both mortality indexes. As shown by Darkiewicz, Hoedemakers (2004) in the case of England and Wales and Arlt, Arltová, Bašta, Langhamrová (2010) for the Czech Republic, Slovakia, Austria and Netherlands, a certain relationship may be identified between the mortality indexes of men $\gamma_{t}^{M}$ and women $\gamma_{t}^{W}$. Therefore the use of a cointegration analysis arises which helps to identify the presence of long-term and short-term relationships. The mortality cointegration indexes $\gamma_{t}^{M}$ and $\gamma_{t}^{W}$ may result 
in the error correction model (EC) (e.g. Arlt, Arltová, 2009), which will subsequently be used for their forecasting. The presence of a long-term relationship will also bind forecasts $\gamma_{t}^{M}$ and $\gamma_{t}^{W}$ and also the forecasts of male and female life expectancy.

\section{Using the Lee-Carter method for forecasting life expectancy in the Czech Republic}

The application of this method on data of the Czech Republic is based on one-year age specific mortality rates at age $x=0,1, \ldots, 100+$ in years 1970-2008 (2008 was chosen so it would be possible to compare forecasts obtained by the LC method with Czech Statistical Office projections, 2009), (Arltová, 2011). In view of the fact that life expectancy is calculated separately for men and women these age specific rates must be available for both sexes.

Figure 6 and Figure 7, which are also called rainbow graphs (Hyndman, Shang, 2010), show one-year age specific male and female mortality rates and the source of these data was the Human Mortality Database (2008) (hereinafter the "HMD"). These graphs have a colour range structured according to rainbow colours so the oldest time series here are dark and the youngest are light. It is clear from these graphs that the mortality fell for both sexes in all cases and the most significant fall was for lower ages and more significant in women than in men.

Figure 6

Logarithms of Age Specific Mortality Male Rates in the Czech Republic in Years 1970-2008

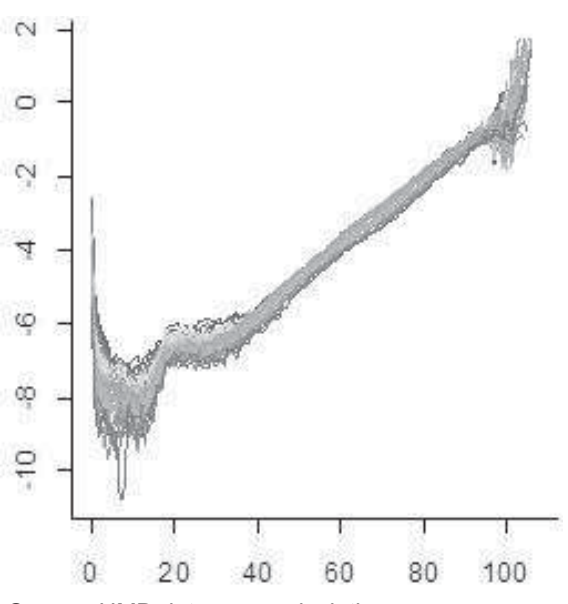

Source: HMD data, own calculations
Figure 7

Logarithms of Age Specific Female Mortality

Rates in the Czech Republic in Years 1970-2008

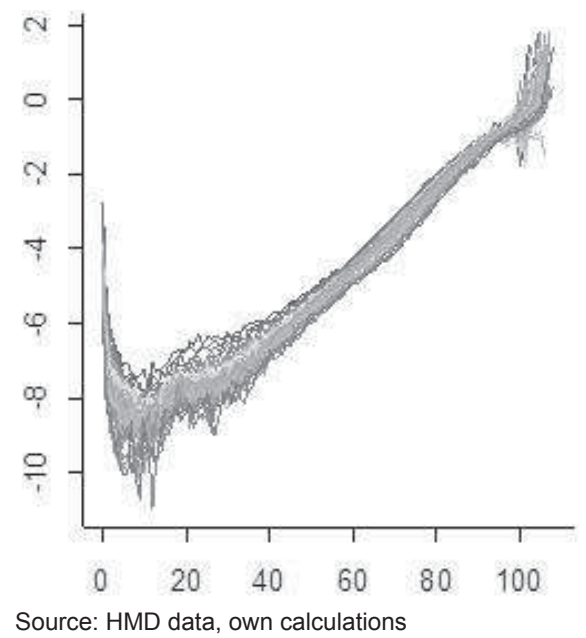

A two-stage Lee-Carter method was subsequently applied to these one-year age specific mortality rates divided according to sex separately for men and women and male and female mortality indexes were calculated ${ }^{1}\left(\hat{\gamma}_{t}^{W}, \hat{\gamma}_{t}^{M}\right)$ (Figure 8).

1 The calculation was made in the R program using the Demography pack (Hyndman, 2011). 
Figure 8

Mortality Indices for Men and Women in the Czech Republic in 1970-2008

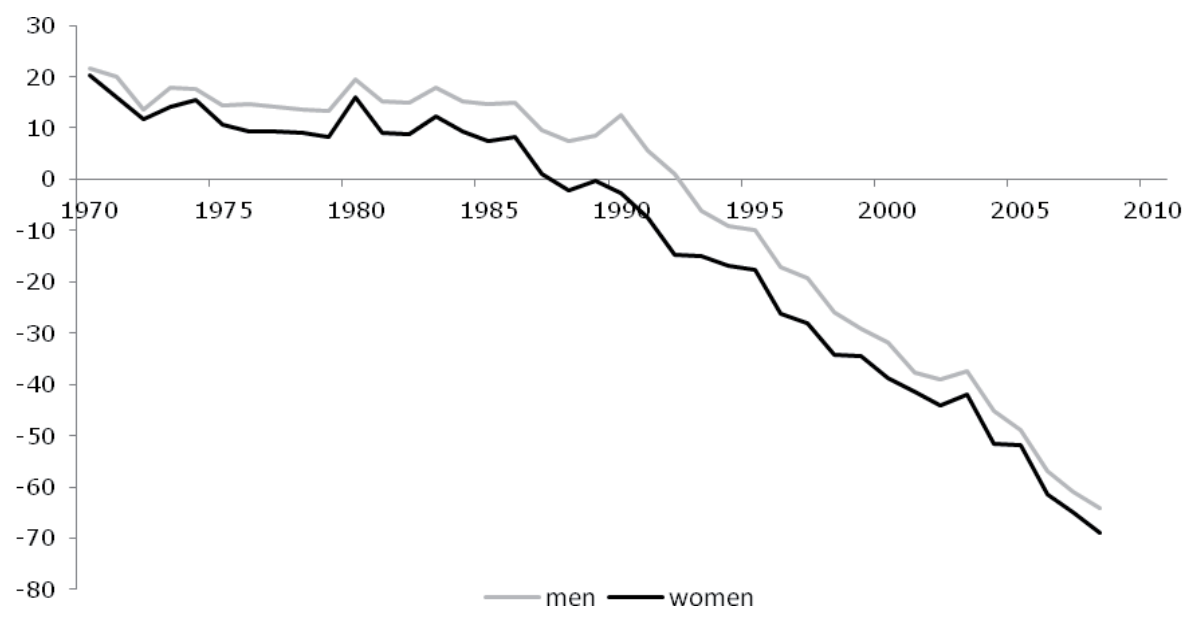

Source: HMD data, own calculations

Both indexes clearly show a significant fall in male and female mortality in the entire monitored period.

Figures 9 and 10 contain an average mortality profile by age and sex $\left(\hat{\alpha}_{x}\right)$ and speed of fluctuation of mortality according to age and sex compared with the total mortality level according to sex $\left(\hat{\beta}_{x}\right)$ in the Czech Republic in years 1970-2008.

Figure 9

Average Mortality Profiles by Age and Sex in the Czech Republic in Years 1970-2008

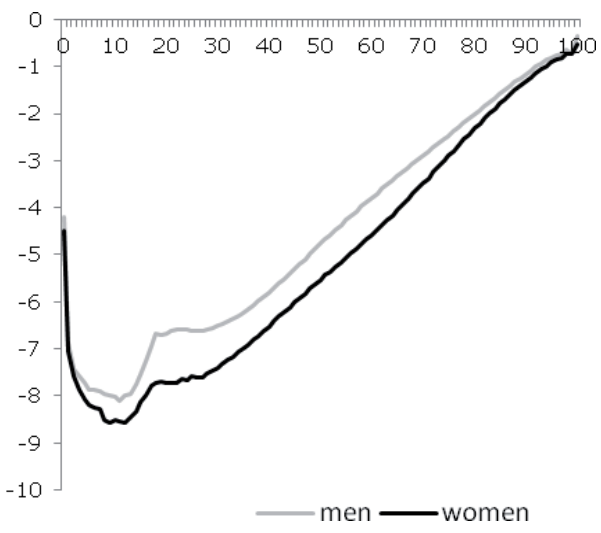

Source: HMD data, own calculation

\section{Figure 10}

Speed of Mortality Fluctuation by Age and Sex Compared with the Mortality Level by Sex in the Czech Republic in Years 1970-2008

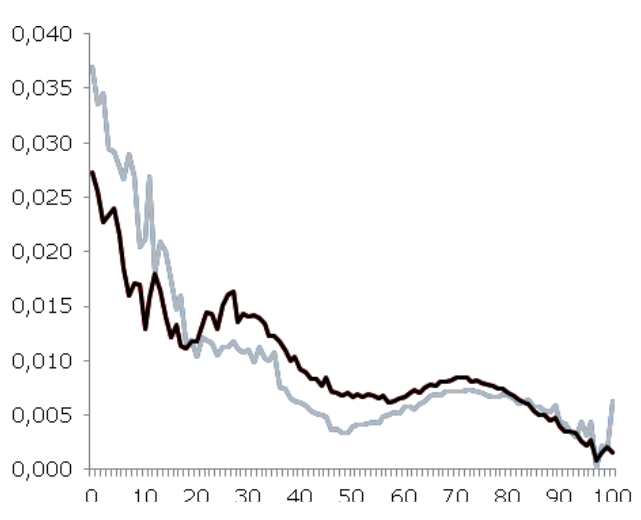


The ADF test of the unit root (Dickey, Fuller, 1979) showed that the male $\hat{\gamma}_{t}^{M}$ and female $\hat{\gamma}_{t}^{W}$ mortality indexes are nonstationary (Table 3 )

Table 3

\section{Unit Root Tests}

\begin{tabular}{|l|c|c|}
\hline $\mathbf{1 9 7 0 - 2 0 0 8}$ & $\mathbf{t}_{\mathrm{ADF}}$ & Prob. \\
\hline$\hat{\gamma}_{t}^{W}$ & 1.773651 & 0.9996 \\
\hline$\hat{\gamma}_{t}^{M}$ & 1.697551 & 0.9996 \\
\hline
\end{tabular}

Source: own calculations

and the multidimensional analysis of time series identified the model $\operatorname{VAR}(1)$ in the form of

$$
\begin{aligned}
& \hat{\gamma}_{t}^{M}=0,718018 \hat{\gamma}_{t-1}^{M}+0,331004 \hat{\gamma}_{t-1}^{W} \\
& \hat{\gamma}_{t}^{W}=-0,26958 \hat{\gamma}_{t-1}^{M}+1,312461 \hat{\gamma}_{t-1}^{W},
\end{aligned}
$$

which shows bilateral dependence $\hat{\gamma}_{t}^{M}$ and $\hat{\gamma}_{t}^{W}$.

The correlation coefficient obtained from the correlation matrix of the residue of model VAR(1) indicates a strong linear dependence $\hat{\gamma}_{t}^{M}$ and $\hat{\gamma}_{t}^{W}$ in the same year $(r=0,896646)$.

Table 4

\section{Correlation Matrix of Model Residues VAR(1)}

\begin{tabular}{|l|c|c|}
\hline $\mathbf{1 9 7 0 - 2 0 0 8}$ & $\hat{\gamma}_{t}^{M}$ & $\hat{\gamma}_{t}^{W}$ \\
\hline$\hat{\gamma}_{t}^{M}$ & 1.00000 & 0.896646 \\
\hline$\hat{\gamma}_{t}^{W}$ & 0.896646 & 1.00000 \\
\hline
\end{tabular}

Source: own calculations

The Johansen cointegration test (Johansen, 1991 and 1995) showed that the system contains one cointegration vector.

Table 5

Johansens Test of Cointegration

\begin{tabular}{|l|r|r|r|}
\hline $\begin{array}{l}\text { Number of Cointegrating } \\
\text { Relations by Model }\end{array}$ & Trace test & $\mathbf{5 \%}$ crit. Value & Prob. \\
\hline 0 & 32.47064 & 25.87211 & 0.0065 \\
\hline 1 & 8.2830 & 12.51798 & 0.2297 \\
\hline
\end{tabular}

Source: own calculations

This cointegration relationship between $\hat{\gamma}_{t}^{M}$ and $\hat{\gamma}_{t}^{W}$ can be expressed in the form of

$$
C_{t}=\hat{\gamma}_{t}^{W}-1,215 \hat{\gamma}_{t}^{M}+11,788-0,502 t .
$$


Tables 6 and 7 contain diagnostic tests of this model.

Table 6

Diagnostic Tests - Portmanteau Test

\begin{tabular}{|l|c|c|c|c|c|}
\hline K & Q-Stat & Prob. & Adj Q-Stat & Prob. & df \\
\hline $\mathbf{1}$ & 1.780899 & 0.9710 & 1.836552 & 0.9683 & 7 \\
\hline $\mathbf{2}$ & 4.842357 & 0.9386 & 5.095523 & 0.9265 & 11 \\
\hline $\mathbf{3}$ & 11.44403 & 0.7205 & 12.35736 & 0.6518 & 15 \\
\hline $\mathbf{4}$ & 13.20611 & 0.8279 & 14.36249 & 0.7622 & 19 \\
\hline $\mathbf{5}$ & 16.60518 & 0.8282 & 18.36854 & 0.7372 & 23 \\
\hline $\mathbf{6}$ & 19.23061 & 0.8614 & 21.57739 & 0.7585 & 27 \\
\hline $\mathbf{7}$ & 23.82751 & 0.8175 & 27.41192 & 0.6513 & 31 \\
\hline $\mathbf{8}$ & 28.03877 & 0.7920 & 32.97079 & 0.5664 & 35 \\
\hline
\end{tabular}

Source: own calculations

Table 7

Diagnostic Tests - Related Tests Jarque-Bera and ARCH

\begin{tabular}{|l|c|l|}
\hline Joint test $\hat{\gamma}_{t}^{M}$ a $\hat{\gamma}_{t}^{W}$ & Test & Prob. \\
\hline Jarque-Bera Test & 1.338436 & 0.8548 \\
\hline Heteroskedasticity Test: ARCH & 8.627839 & 0.1956 \\
\hline
\end{tabular}

Source: own calculations

Figure 11

Indices of Mortality by Sex with Predictions for $\mathbf{2 0 5 0}$

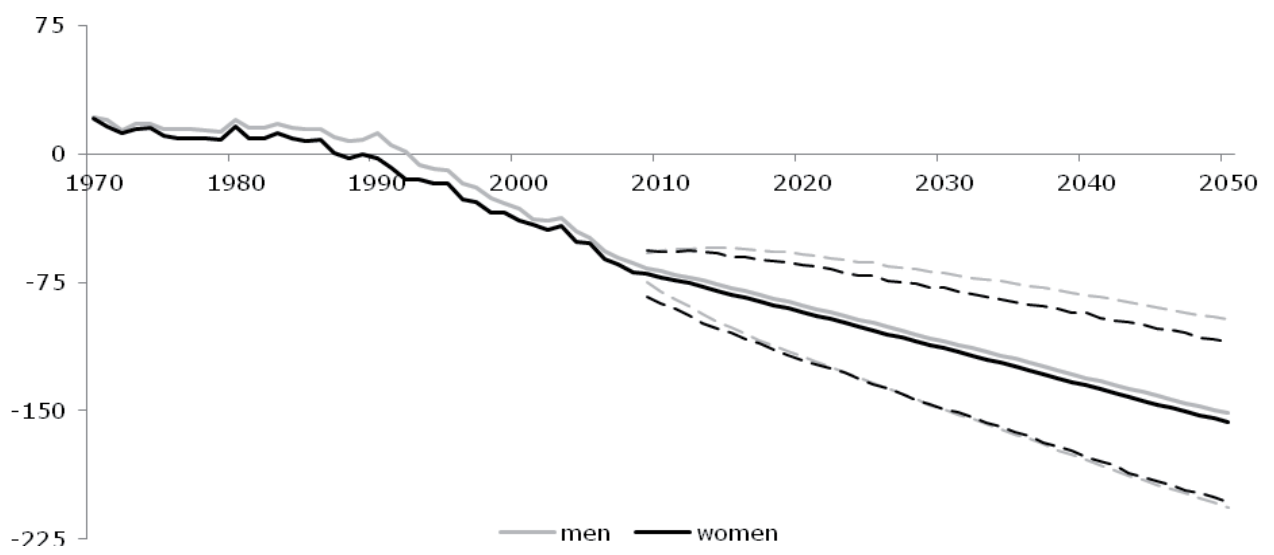

Source: own calculations 
Using an estimated model it is then easy to construct a forecast for both mortality indexes. The forecast horizon selected was $h=42$, i.e. 2050 (for comparability with CSO projections, 2009). Figure 11 contains points and $95 \%$ interval forecasts of both indexes. The interval forecasts were obtained by simulation $(n=1000)$. It is evident that forecasts calculated using the cointegrated Lee-Carter method are interlinked and do not diverge in time.

Figure 12

Logarithms of Forecasts of Age Specific Male Mortality Rates in the Czech Republic in Years 2009-2050
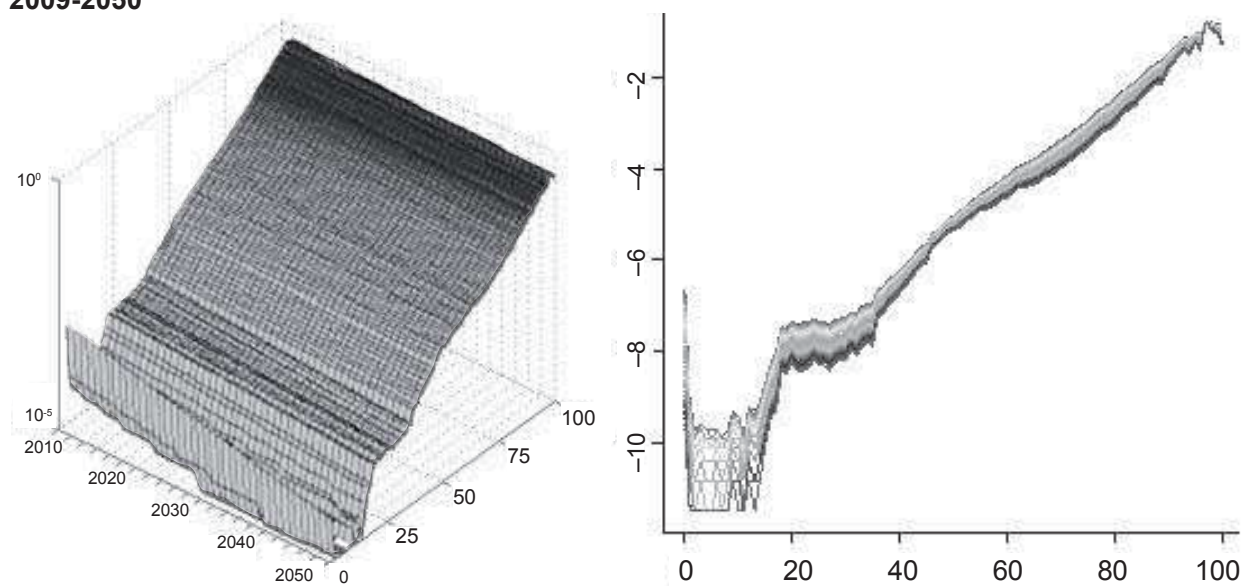

Source: own calculations

Figure 13

Logarithms of Forecasts of Age Specific Female Mortality Rates in the Czech Republic in Years 2009-2050
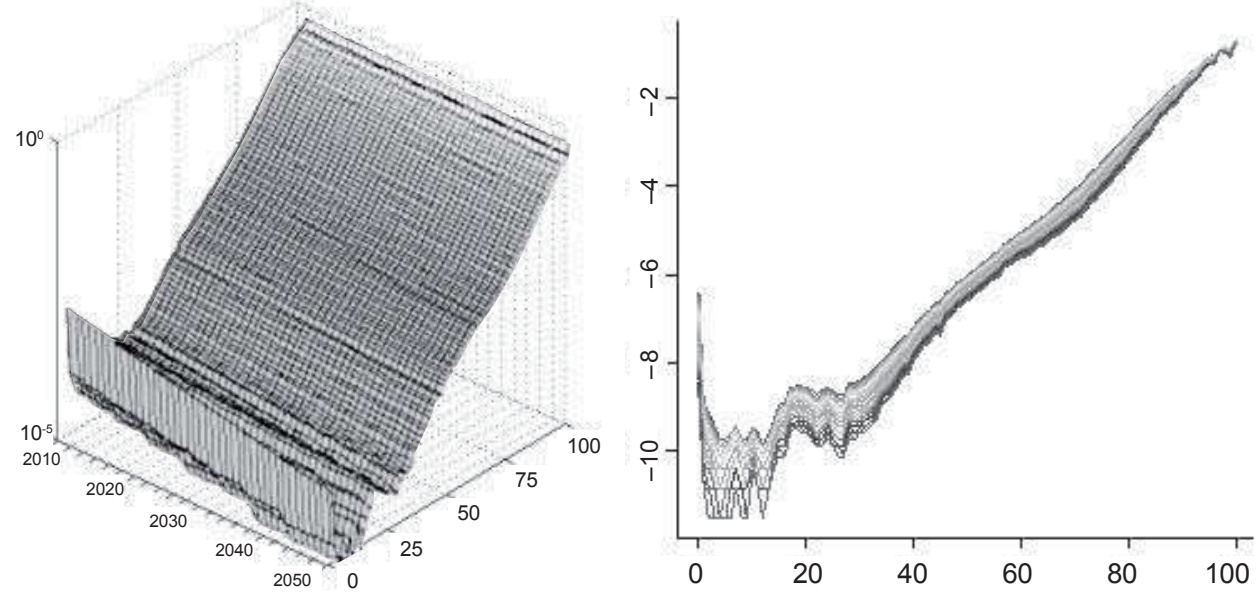

Source: own calculations 
Estimates of age specific male and female mortality rates can then be easily kept count of from the relationship of

$$
\hat{m}_{x, t}=e^{\hat{\alpha}_{x}+\hat{\beta}_{x} \hat{\gamma}_{t}}, x=0, \ldots, 100+, t=2009, \ldots, 2050,
$$

i.e. for men and women separately. Figure 14 and Figure 15 contain their graphs (in a logarithmic scale) in the form of points forecasts of age specific male and female mortality rates in the Czech Republic for years 2009-2050.

Forecasts for life expectancy at birth of men and women for years 2009-2050 (Figure 14) can then easily be kept count of from calculated forecasts of age specific mortality rates.

\section{Figure 14}

Development of Life Expectancy of Men and Women in the Czech Republic with Points and Intervals Forecasts for Years 2009-2050 Calculated on the Basis of the LC Method and Czech Statistical Office Projections

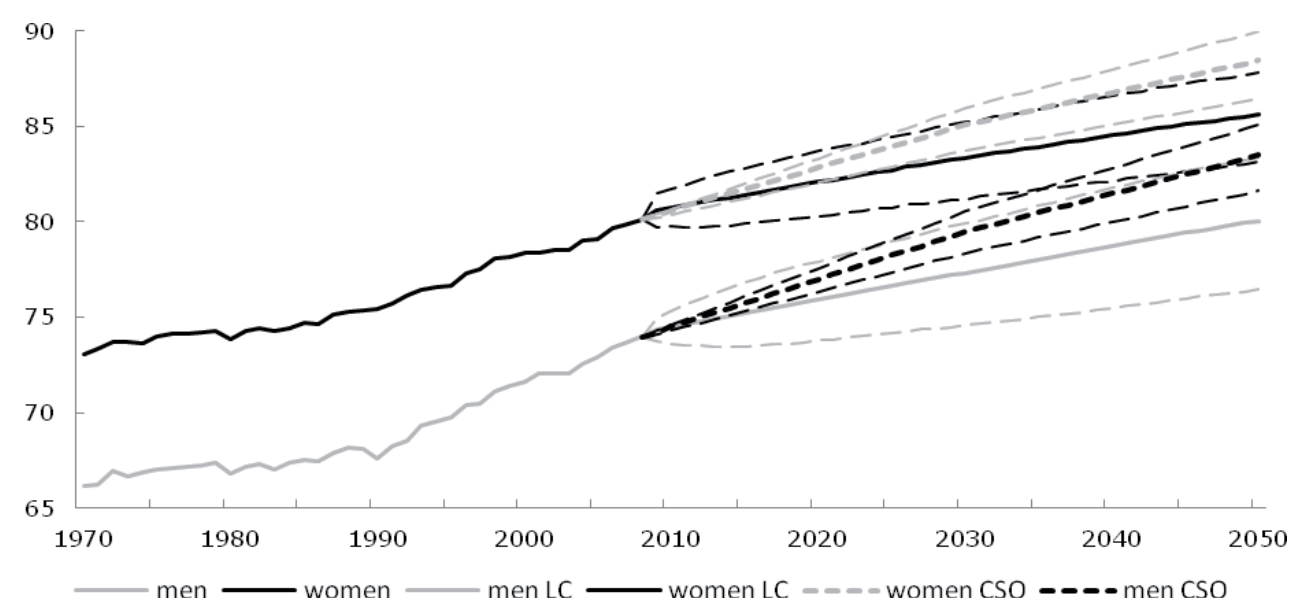

Source: CSO, HMD data, own calculations

Point forecasts obtained by the cointegrated LC method grow very slowly in the monitored period. In case of life expectancy at birth of men the value is from 73.95 years in 2008 to the value of 80.05 years in 2050 and in case of life expectancy at birth for women the value is from 80.13 years in 2008 to the value of 85.63 years in 2050 .

The comparison of the forecast of life expectancy of men and women obtained on the basis of the cointegrated Lee-Carter method with the results obtained from the Czech Statistical Office projections (ČSÚ, 2009) is shown in Table 9. 
Table 8

Points Forecasts of Life Expectancy of Men and Women in Selected Years

\begin{tabular}{|l|c|c|c|c|}
\hline & \multicolumn{2}{|c|}{ Men } & \multicolumn{2}{c|}{ Women } \\
\hline Year & Čso & LC & Čso & LC \\
\hline $\mathbf{2 0 1 0}$ & 74.5 & 74.48930 & 80.6 & 80.78002 \\
\hline $\mathbf{2 0 2 0}$ & 77.0 & 75.91466 & 82.8 & 82.08488 \\
\hline $\mathbf{2 0 3 0}$ & 79.5 & 77.32583 & 85.1 & 83.33124 \\
\hline $\mathbf{2 0 4 0}$ & 81.5 & 78.73220 & 86.8 & 84.52260 \\
\hline $\mathbf{2 0 5 0}$ & 83.5 & 80.05289 & 88.4 & 85.63636 \\
\hline
\end{tabular}

Source: data, CZSO, own calculations

The points forecasts obtained from official Czech Statistical Office forecasts (medium variant) reach higher values of life expectancy in 2050 in the case of both sexes compared with the LC method. Regarding men the value is from 73.95 years in 2008 to the value of 83.5 years compared with 80.05 years in the cointegrated Lee-Carter method, and in case of women the Czech Statistical Office projection reaches the value of 88.64 years compared with 85.64 years by the cointegrated LC method.

\section{Conclusion}

In the Czech Republic more significant changes in mortality have appeared in recent years in the early 1990s. In this period there was a more significant fall in mortality. There is a fall in mortality above all in medium and higher ages. More and more people live to a higher age. The number and share of old people in the population is increasing. Changes are taking place in the population age structure with the long-term and significant fall in the Czech Republic of total fertility below the limit of simple reproduction and simultaneous prolongation of expectation of life at birth. The number of people of older and oldest age groups is increasing. In economic terms there is also an increasing share of people of a post-productive age.

In Western Europe a quantitatively new type of decline in the level of mortality took place about thirty years ago which is described as the end of the third stage of the epidemiological transition, or its fourth stage. This stage is a period when degenerative and civilisation diseases predominate as classes of the causes of death. What is characteristic for this is the unexpected fall in mortality at a greater age. The intensity of death to cardiovascular diseases is falling above all. The Czech Republic has a certain delay in the development of mortality compared with developed countries. The fact that in recent years there was a fall in mortality is explained by the delay compared with the rest of Europe in the treatment of diseases of the circulatory system. In the 1950s antibiotics were applied en masse in the Czech Republic. However, at this time there were no investments into very costly technologies and instruments which allowed the treatment of diseases of the circulatory system. Drugs for the prevention and treatment of diseases of the circulatory system were not available to most of the population until 
after 1990. In Western Europe these methods and drugs had already been applied at the turn of the 1970s. Great advance came in the so-called by-pass, a surgical procedure to circumvent the damaged heart vessels. Promotion and maintaining a healthy lifestyle also play an important role in reducing mortality and related issues of the prevention of diseases and promotion of responsibility for one's own health. The promotion of physical activity, monitoring cholesterol levels, overweight, increased blood pressure, offer of healthy nutrition, discouragement of smoking, alcohol consumption is a far more matter of course today.

The Czech Republic has a greater chance of further prolonging life expectancy by reducing mortality at middle age above all for diseases of the circulatory system and malignant neoplasms.

The fact that mortality developed and, as arises from our estimate (and from the estimate of the Czech Statistical Office) will continue to develop favourably, is a great success for a developed society. However, on the other hand it is a challenge for economists and for the pension funds. Society will have to solve a number of economic problems which arise from the changing relation between the population in a post-productive and economically active age. Pension funds will have to reassess or make their assumptions more specific about the development of mortality on which their financial plans are based. The aging of the population depends on a number of other areas and in this context economists talk of the so-called silver economy which is targeted at fellow-citizens. Today many businessmen and manufacturers realise that room is appearing for products and services geared towards older age groups. The fact that the number of people in older and the oldest age groups is increasing significantly must be considered and society must adapt to this because older people will also form a highly significant electoral base. The ageing population and problem of longevity is currently becoming a highly discussed topic. It is not only the foreground of interest to demographers and economists. It is becoming a constantly more often discussed topic in connection with the further social and political development of society. Of course the process of an ageing population must be looked at not only in terms of prolonging age. Demographic ageing must be understood as a new challenge for society. There are a number of issues as to whether society can cope in future with double the number of senior citizens and how the system of social and health care will be changed in this context. However it must be realised that Czech society is gradually becoming a longevity society. As has already been stated, these changes, which are the result of changes in mortality, will have an impact on a number of areas of society. For example, there will have to be greater focus in the area of healthcare and medicine on prevention so that people can live to a greater age in a relative good state of health. The structure of the labour market will also have to change. This also relates to changes in the education system when the system of lifelong learning will also have to be extended. Issues relating to migration are a separate question.

Ageing population trends cannot be reversed by pro-population measures, they can only be moderated. Extraordinary attention needs to be paid in advance to the problems of an ageing population. 


\section{References}

Arlt, J., Arltová, M. (2009), Ekonomické časové řady. Professional Publishing.

Arlt, J. Arltová, M., Bašta, M., Langhamrová, J. (2010), "Cointegrated Lee-Carter Mortality Forecasting Method." Paris 22.08.2010 - 27.08.2010. In COMPSTAT 2010. Paris: CNAM and INRIA, pp. 713-720.

Arltová, M. (2011), "Stochastické metody modelování a předpovídání demografických procesů." Thesis, University of Economics, Prague.

Box, G. E. P., Jenkins, G. M. (1970), Time Series Analysis, Forecasting and Control. Holden-Day, San Francisco.

Brounhs, N., Denuit, M., Vermunt, K. J. (2002), "A Poisson Log-bilinear Regression Approach to the Construction of Projected Lifetables." Insurance: Mathematics and Economics 31, pp. 373-393.

Čsú (2009), Projekce obyvatelstva České republiky do roku 2065. Praha: Čsú.

Darkiewicz, G., Hoedemakers, T. (2004): How the Co-integration Analysis Can Help in Mortality Forecasting. Actuarial Science Research Group, Catholic Univ. of Leuven. Available at http://www. econ.kuleuven.ac.be/tew/academic/actuawet/pdfs/MortalityFinal_JAP_23022004.pdf. [14. 11. 2010].

Dickey, D. A., Fuller, W. A. (1979), "Distribution of the Estimators for Autoregressive Time Series with a Unit Root." Journal of the American Stat. Association, 74, pp. 427-431.

Granger, C. W. J. (1969), "Investigating Causal Relations by Econometric Models and Cross-Spectral Methods." Econometrica 36, pp. 424-438.

Härdle, W., Myšičková, A. (2009), "Stochastic Population Forecast for Germany and its Consequence for the German Pension System." SFB 649 Discussion Papers SFB649DP2009-009, Humboldt University, Berlin, Germany.

Human Mortality Database (2008) University of California, Berkeley and Max Planck Institute for Demographic Research.

Hyndman, R. J. (2011), "Demography: Forecasting Mortality, Fertility, Migration and Population Data, R package v. 1.09."

Hyndman, R. J., Shang, H. L. (2010), "Rainbow Plots, Bagplots and Boxplots for Functional Data." Journal of Computational \& Graphical Statistics 19(1), pp. 29-45.

Johansen, S. (1991), "Estimation and Hypothesis Testing of Cointegration Vectors in Gaussian Vector Autoregressive Models." Econometrica, 59, pp. 1551-80.

Johansen, S. (1995), Likelihood-based Inference in Cointegrated Vector Autoregressive Models. Oxford, Oxford University Press.

Kretschmerová, T., Šimek, M. (2001), "Populační prognóza České republiky do roku 2030." Available at http://www.czso.cz/cz/cisla/1/18/archiv/ademogr/dem0003/projekce.htm. [28. 2. 2011].

Kučera, M. (1990), Budou se Evropané dožívat věku sta let? Praha: Panorama, pp. 419-455.

Langhamrová, J. (2010), "Vývoj střední délky života obyvatel České republiky v letech 1960-2008." Bc. thesis, University of Economics, Prague.

Lee, R. D., Carter, L. R. (1992), "Modeling and Forecasting U.S. Mortality." Journal of the American Statistical Association, 87, pp. 659-671.

Lee, R. D., Miller, T. (2001), "Evaluating the Performance of Lee-Carter Mortality Forecasts." Demography 38(4), 537-549.

Rabušic, L. (1993), “Kde jsou meze délky lidského života?” Demografie, 35(3), pp. 153-161.

Renshaw, A., Haberman, S. (2003), "Lee-Carter Mortality Forecasting: A Parallel Generalized Linear Modelling Approach for England and Wales Mortality Projections." Applied Statistics, 52 (1): pp. 119-137.

Wilmoth, J. (1993), "Computational Methods for Fitting and Extrapolating the Lee-Carter Model of Mortality Change." Technical report Department of Demography, University of California, Berkeley.

Wolf, J. a kol. (1982), Umění žít a stárnout. 1. vyd. Praha: Svoboda. 